\title{
Psychological factors associated with use of home nebulized therapy for COPD
}

\author{
C.M. Bosley*, Z.M. Corden**, P.J. Rees**, G.M. Cochrane**
}

\begin{abstract}
Psychological factors associated with use of home nebulized therapy for COPD. C.M. Bosley, Z.M. Corden, P.J. Rees, G.M. Cochrane. (C)ERS Journals Ltd 1996.

ABSTRACT: This study examined the relationship between adherence to domiciliary nebulized therapy and psychological factors; patient attitudes, anxiety, depression, and quality of life.

Ninety three patients aged 45-77 yrs with chronic obstructive pulmonary disease (COPD) and using domiciliary nebulizers were recruited from a hospital database. They completed the St George's respiratory questionnaire (SGRQ)-1 and the hospital anxiety and depression scale (HADS) and attended a semistructured interview. Their usual nebulizers were replaced by Dataloggers, which record the date, time and duration of each treatment, to use for 4 weeks. The SGRQ was then repeated (SGRQ-2).

Eighty two patients completed the study. Fifty six percent were poorly adherent; taking less than $70 \%$ of the dose prescribed (or less than $60 \%$ on regimens of $\geq 5$ times daily). The total scores on the SGRQ-2 were negatively correlated with percentage adherence. Multiple regression analysis showed that the SGRQ-2 total score was associated with percentage adherence, depression score, feeling supported by clinic staff, and patients feeling that they tried to ignore their chest disease.

Patients who report poor quality of life are more likely to be depressed, feel unsupported by clinic staff and be poorly adherent to treatment. Increased levels of clinic support, with the addition of psychological treatments, may be of benefit to some patients with chronic obstructive pulmonary disease.
\end{abstract} Eur Respir J., 1996, 9, 2346-2350.

Depts of *Psychiatry and **Allergy and Respiratory Medicine, United Medical and Dental Schools, Guy's Hospital, London, UK.

Correspondence: G.M. Cochrane

Dept of Allergy and Respiratory Medicine Ground Floor Out-Patients

Guy's Hospital

London SE1 9RT

UK

Keywords:

Chronic obstructive pulmonary disease patient compliance patient psychology

Received: January 91996

Accepted after revision July 51996

This study was supported by an educational grant from Allen and Hanbury's.
Previous studies of asthma and chronic bronchitis have shown that at least half of patients take less than $75 \%$ of the inhaled medication prescribed [1-4]. In separate studies, poor adherence to inhaled bronchodilator and inhaled corticosteroid has been associated with increased morbidity in asthma and chronic bronchitis, respectively $[3,5]$. Patients with severe respiratory disease are often prescribed nebulized medication to use regularly at home. At Guy's Hospital, they are first assessed to ascertain whether they derive any measurable benefit from nebulized medication, and they are then dispensed a domiciliary, portable nebulizer and compressor unit. Drugs used in the nebulizer include bronchodilators, anticholinergics and corticosteroids, and patients may be prescribed regimens ranging from twice to six times daily. The hypothesis under examination was that patients' use of their home nebulizers is associated with symptoms and quality of life and is affected by psychological factors. In this study, we aimed to examine the relationship between these factors and patient use of nebulizers.

\section{Material and methods}

\section{Study subjects}

One hundred and twenty nine patients (64 males and 65 females), aged 40-75 yrs, with a diagnosis of asthma, emphysema or chronic bronchitis and using home nebulizers, were identified using a hospital database. They were contacted by letter and telephone; 93 agreed to take part in the study and 82 completed, of whom 44 (54\%) were male. The mean age of the group was 65 yrs (range 45-77 yrs) and mean duration of illness was 15.9 yrs (range 1-66 yrs). The majority of the participants were suffering from chronic obstructive bronchitis, with varying degrees of emphysema (74\%). Nineteen patients had asthma, one bronchiectasis and one fibrosis (rheumatoid arthritis). All groups were given the same psychological assessment since the groups were too small for separate assessment and analysis. Eleven (13\%) patients were using inhaled corticosteroids. The mean age of the 36 who refused to take part was 65 (SD 7.9, range 42-75) yrs. Twenty one $(58 \%)$ gave no reason or were not interested, $10(28 \%)$ said they were not well enough, two $(6 \%)$ did not wish to participate in questionnaires and interviews, one owned their own nebulizer, one was too busy at work and one was starting acupuncture therapy.

\section{Study design}

Patients were given Dataloggers (see below) to use over a period of 4 weeks, while their usual nebulizers were kept by the hospital and serviced. Patients were given a demonstration and written instructions on how 
to use the Datalogger. The treatment regimen prescribed was checked against medical notes and confirmed with the patient. Each patient attended for an interview and completed two self-rating questionnaires; the Hospital Anxiety and Depression Scale (HADS) [6] and the St George's Respiratory Questionnaire (SGRQ) [7]. At the end of the 4 week study period, patients returned their Datalogger and repeated the SGRQ.

\section{Instruments}

Monitoring of nebulizer use. The Dataloggers were provided by Medicaid. Each comprised a CR50 compressor and a Ventstream nebulizer, which had been connected to a data collection system. The system consists of a processor which collects pressure data from the Ventstream mouthpiece via a sensor and an analogue-to-digital converter. The system also has an input from a pressure switch on the output of the compressor, which checks that the nebulizer is connected to the system. The Datalogger recorded the date, time and duration of each treatment. Inhalation time (time spent inhaling the treatment) was recorded by the pressure sensor on the mouthpiece, which trips in at $\pm 15 \mathrm{~L} \cdot \mathrm{min}^{-1}$. The Datalogger has a downloading facility so that the data could be read into an IBM computer. These compressors deliver the treatment dose in approximately $8 \mathrm{~min}$, as compared with 15 min which was usual for the nebulizers currently in use by the patients. A dose was considered valid when the duration of treatment was at least 2 min and there was evidence of inhalation.

Interview. In a semistructured interview, based on one used for asthma patients [8], patients were encouraged to talk about their lives in relation to their chest disease. Demographic and other background details were recorded. The items covered: feelings of anger, shame, secrecy and denial; reports of past illness and past compliance with treatment; reports of self-care in general and in relation to their chest disease, including present adherence with medication; relationships with doctors and other clinic staff; support from family and partners; perceptions of treatment, its efficacy and drawbacks. Questions were phrased to permit the patients to give a negative or less socially acceptable answer. The interviewer discussed each item with the patients until they were satisfied that understanding had been reached. The item was then scored by the patient on a 5-point scale, according to strength of feeling.

$H A D S$ [6]. This is a 14 item self-rating questionnaire designed to screen for anxiety and depression in patients with physical illness; it therefore excludes somatic symptoms of psychological disorder. It contains a depression subscale, and an anxiety subscale, each scoring from 0 to 21. A score of 11 or over identifies patients with a high probability of suffering from a mood disorder, while a score of $8-10$ indicates the possible presence of a mood disorder.

$S G R Q$ [7]. This is a 76 item self-rating questionnaire for measuring health in chronic airflow limitation. A total score is obtained, along with scores for three subscales:
1) Symptomatology, i.e. levels of coughing, wheezing, breathlessness and sputum production; 2) Activity, i.e. activities which exacerbate or are limited by breathlessness); and 3) Impact, i.e. impact on aspects of daily life, such as employment, and feelings of stigma. Each item of the questionnaire is weighted. The total score ranges $0-100$, where the higher the score obtained, the more impairment in quality of life is indicated. The original questionnaire poses questions relating to the previous year of the patient's life. For this study, it was adapted so that the questions related to the previous 4 weeks only.

\section{Statistical analysis}

Adherence to nebulizer treatment was calculated as:

$$
\% \text { adherence }=\frac{\text { number of doses taken }}{\text { number of doses prescribed }} \times 100
$$

Pearson's correlation was used to examine the association between adherence, SGRQ scores and HADS scores. Chi-squared test and independent t-tests were used to compare demographic data between patients who participated in the study and those who did not, and those who withdrew from the study and those who completed. Chi-squared test and independent t-tests were used to compare demographic and interview data between patients in the adherent and nonadherent groups. A multiple regression analysis (forward stepwise method) was performed with the total SGRQ as the dependent variable.

\section{Results}

Withdrawals from the study

Eleven subjects withdrew from the study, 7 (64\%) females and $4(36 \%)$ males. The mean age of this group was 64 (SD 8) yrs. Four subjects $(36 \%)$ experienced worsening symptoms and felt safer using their own machine, four $(36 \%)$ found the Datalogger difficult to use, and the remaining three were withdrawn due to a hospital admission, a diagnosis of lung cancer and a nebulizer recording malfunction. There was no statistical difference between the group who were withdrawn and the group who completed the study on demographic factors.

\section{Adherence}

The mean percentage adherence of the group was $57 \%$ (range $0-124 \%$ ). A full report and description of Datalogger use is to be described elsewhere. Patients on regimens of up to four times daily who took less than $70 \%$ of the dose prescribed, and those on regimens of five times daily or over who took less than $60 \%$ of the dose prescribed, were defined as poorly adherent. These levels of adherence were judged likely to result in clinical consequences by the chest physicians involved in the study (GMC and PJR). Using this definition, 46 patients $(56 \%)$ were poorly adherent. 
Table 1. - St George's Respiratory Questionnaire (SGRQ) after 4 weeks of the study

\begin{tabular}{lccc}
\hline SGRQ & Nonadherent & Adherent & Total \\
\hline Impact & $55.3(13.7)$ & $53.2(17.6)$ & $54.5(15.5)$ \\
Activity & $81.7(18.6)$ & $81.3(13.7)$ & $81.8(16.5)$ \\
Symptoms & $69.6(17.3)$ & $65.7(18.9)$ & $68.0(18.0)$ \\
Total & $65.4(13.1)$ & $63.8(13.9)$ & $64.9(13.4)$ \\
\hline
\end{tabular}

Values are presented as mean, and SD in parenthesis.

\section{Demographic factors}

Age was correlated with percentage adherence (coefficient $=0.26 ; \mathrm{p}=0.02$ ). Sex, duration of illness, marital status and social class were not linked to adherence.

\section{$S G R Q$}

All patients completed the SGRQ at the start of the 4 weeks (SGRQ-1). This reflected the status of the patients in the 4 weeks prior to entering the study. There was no correlation between percentage compliance and any scores on the SGRQ-1. Seventy eight patients completed the SGRQ at the end of the study (SGRQ-2). The mean scores for the subscales and the total are given in table 1 . The total scores on the SGRQ-2 were negatively correlated with percentage adherence $(\mathrm{r}=-0.25 ; \mathrm{p}=0.03)$. Negative correlation was also found between the symptom subscale $(\mathrm{r}=-0.22 ; \mathrm{p}=0.05)$ and the impact subscale $(\mathrm{r}=-0.22 ; \mathrm{p}=0.05)$.

\section{$H A D S$}

Seventy six patients completed the HADS. The mean score for the whole group on the depression subscale was 8 (SD 4.1, range $0-18$ ) and on the anxiety subscale was 9 (SD 4.3, range 0-18). The number of probable cases of depressive disorder was $19(20 \%)$, and the number of probable cases of anxiety disorder was 26 $(28 \%)$. Both the anxiety and depression subscale scores correlated with the SGRQ-2 total score ( $\mathrm{r}=0.39, \mathrm{p}=0.001$; and $\mathrm{r}=0.44, \mathrm{p}<0.001$, respectively), and with each other $(r=0.60 ; p<0.001)$, but were not related to the percentage adherence.

\section{Interview}

Background information. Fifty four percent of the patients had another chronic illness, $61 \%$ had experienced a serious illness in the past, and $11 \%$ had a history of past psychiatric illness requiring treatment. Ninety percent of the group were retired from work. Six percent of the group were nonsmokers, $71 \%$ were ex-smokers, and $22 \%$ were still smoking. Sixty one percent of the smokers were nonadherent, but there was no significant difference between adherent and nonadherent groups.

Self-report of adherence. Patients were asked how often they missed doses from their nebulizers. Sixty six percent stated that they never missed doses $(61 \%$ of the nonadherers and $72 \%$ of the adherers). Six percent reported missing doses only once a month. Ten percent admitted to missing doses once a week, and $7 \%(11 \%$ of the nonadherers and 3\% of the adherers) stated that they missed a dose once a day. Eleven percent $(11 \%$ of both adherers and nonadherers) stated that they only used the nebulizer when they felt they needed to. There was no significant difference between the groups. Patients were asked simple questions to establish if they had a basic understanding of their nebulized medication (e.g. did they know what medications they used and how often, and did they know that the medications had a bronchodilatory or anti-inflammatory effect). Fifty two percent of patients were not able to answer these questions correctly, although $91 \%$ believed that they did understand the treatment they were prescribed. Of those who were unable to answer correctly, $60 \%$ were nonadherent.

Scores for the remaining items are given in table 2 . The adherent and nonadherent groups have not been shown separately as there were no differences in scores between them.

Table 2. - Interview items: patients responses $(n=82)$

\begin{tabular}{lccc}
\hline Item & Agree & Disagree & Don't \\
& $\%$ & 55 & know \\
\hline I try to ignore my chest disease (act as if it doesn't exist) & 43 & 49 & 2 \\
I feel angry about my chest disease & 51 & 65 & 0 \\
I feel ashamed or embarrassed about my chest disease & 33 & 82 & 2 \\
I gain some benefit when I am sick & 18 & 5 & 0 \\
I take good care of myself & 95 & 89 & 6 \\
I feel guilty about taking time to look after myself & 5 & 6 & 0 \\
I avoid doing the things I should to care for myself & 94 & 62 & 0 \\
I haven't looked after myself when I have been ill & 34 & 6 & 7 \\
in the past & & 38 & 0 \\
I usually follow my doctor's advice & 94 & 43 & 3 \\
I feel that I am not in control of my chest disease & 55 & 34 & 2 \\
I can take my troubles to my partner & 57 & 25 & 4 \\
My partner gives me support with my chest disease & 66 & 5 & 5 \\
I feel supported by others in my life & 94 & 48 & 89 \\
I feel supported by the clinic staff & 91 & 1 & 94 \\
I understand the treatment prescribed & 48 & 1 & \\
I believe the treatment is helpful & 10 & 5 & \\
Something about the treatment stops me from taking it & 5 & & 0 \\
Something about me stops me taking the treatment & & 48
\end{tabular}


Table 3. - Model obtained by multiple regression analysis: SGRQ-2 score as outcome variable (forward stepwise regression)

\begin{tabular}{|c|c|c|c|c|}
\hline Variable & $\mathrm{r}$ & $\mathrm{SE}^{*}$ & $\mathrm{~T}$ & Sigma $\mathrm{T}$ \\
\hline$\%$ adherence & -0.158 & 0.044 & -0.375 & 0.0007 \\
\hline Depression score & 1.536 & 0.399 & 0.395 & 0.0003 \\
\hline $\begin{array}{l}\text { Support from } \\
\text { clinic staff }\end{array}$ & -6.601 & 2.487 & -0.289 & 0.0103 \\
\hline $\begin{array}{l}\text { Try to ignore } \\
\text { chest disease }\end{array}$ & -3.800 & 1.134 & -0.338 & 0.0014 \\
\hline$=$ & 0.445 & & & \\
\hline $\begin{array}{l}\text { Adjusted } r^{2} \\
\text { SE }\end{array}$ & $\begin{array}{l}0.406 \\
0.92\end{array}$ & & & \\
\hline
\end{tabular}

$\mathrm{T}$ : test statistic for deriving probability. *: SE of regression coefficient $(r)$.

Items from the interview, demographic data and percentage adherence were entered into a multiple regression analysis (using forward stepwise regression) with the SGRQ total score as the outcome variable. The model obtained is shown in table 3. Significant factors were: percentage adherence; depression score; feeling supported by clinic staff; and feeling that they tried to ignore their chest disease. The final model accounted for $40 \%$ of the variance.

\section{Discussion}

Patients with COPD who are given domiciliary nebulizers are those who are experiencing high levels of morbidity and whose symptoms are not fully controlled by medications delivered by simpler devices. Despite this, the study found that they are no more likely than other patient groups to take their medications as often as prescribed. Some previous studies have shown that increasing age is associated with increasing adherence $[4,9]$, possibly because older people may have learned from their own experience how best to manage their disease. The group of patients in this study were from the older age groups, but there was still a high level of nonadherence. Although age was correlated with adherence, this effect did not remain in the multiple regression analysis. Previous studies [10] have shown that adherence is not dependent on the severity or duration of illness.

The group as a whole had a high prevalence of probable anxiety $(28 \%)$ and depressive $(20 \%)$ disorders. This compares with previous studies, such as that by YeLLOWLEES et al. [11], which found a prevalence of 34\% (anxiety) and $16 \%$ (depressive) disorder in an unselected sample of 50 patients admitted to a respiratory unit with chronic airflow obstruction. Both anxiety and depression scores were correlated with the SGRQ scores, although when entered into the multiple regression analysis, only depression remained as a significant factor. It may be that people with psychological symptoms are more likely to report respiratory symptoms (for example, they may experience breathlessness due to hyperventilation) [12]. However, this would seem more likely to occur with predominantly anxiety disorders, and increasing anxiety has been shown to be associated with increasing respiratory disability in an earlier study [13]. Patients who are depressed may be more likely to view their condi- tion in a pessimistic manner and report increased disability. Conversely, increased disability may be a cause of a depressed mood. It seems likely that respiratory disability and depression interact and exacerbate each other, increasing the patient's distress. Depression may cause a patient to neglect themselves and their treatment and influence respiratory symptoms by being a cause of nonadherence. However, depression scores were not found to be significantly higher in the nonadherent group, in contrast to a previous study examining the psychological factors associated with adherence in asthma [6]. However, the group in the present study were older (mean 65 yrs, compared to 45 yrs in the previous study), had more severe chest disease, and also had higher overall prevalence of psychiatric disorder as indicated by the HADS. These factors may account for the difference in findings.

In contrast with TURNER et al. [14], who found no association between adherence to nebulized treatment and reports of the effects of illness on daily functioning, this study found that increased impairment in quality of life was associated with poor adherence to treatment. The SGRQ score at the start of the study (reflecting the patients' experience in the 4 weeks prior to the study) was not correlated with the subsequent adherence, but the SGRQ score at the end of the study (reflecting the patients' experience over the period that adherence was measured) was negatively related to percentage adherence. This is consistent with the view that adherence is not consequent on previous experience of illness but is related to current problems. Poor quality of life was also associated with increased depression scores. Patients who reported that they did not find clinic staff to be supportive and those who did not try to ignore their chest disease were also more likely to have increased impairment in their quality of life. The latter association is of interest, in that it supports the theory that some level of denial may be helpful in coping with chronic chest disease (although too much may be counter-productive as symptoms may not be acted upon) $[15,16]$.

In conclusion, domiciliary nebulizers are an expensive method of delivering medication. They are cumbersome, time-consuming and inconvenient to use, but if a patient's clinical condition is such that they are in need of such therapy it is important that every effort should be made to enable them to gain the maximum benefit possible. As Mellins et al. [17] suggest in their editorial, the effective use of therapeutic advances in medicine depends upon developing effective communication and education and enabling patients to respond effectively to their health conditions and personal circumstances.

Patients who report poor quality of life (including impairment of activity, symptoms and impact) due to their chest disease are more likely to be depressed, and to feel unsupported by their professional medical helpers, and are more likely to be poorly adherent to treatment. Although the direction of causality cannot by inferred from the results of this study, it is reasonable to suggest that increased levels of clinic support, including efforts to increase adherence to treatment and the possible inclusion of psychological treatments in management plans, may be of benefit to patients with chronic severe chest disease. 
Acknowledgements: The authors would like to thank Medicaid for the provision of the Dataloggers and their technical support and advice.

\section{References}

1. Bosley CM, Parry DT, Cochrane GM. Patient compliance with inhaled medication. Does combining betaagonists with corticosteroids improve compliance? Eur Respir J 1994, 7: 504-509.

2. Mawhinney H, Spector SL, Kinsman RA, et al. Compliance in clinical trials of two nonbronchodilator, antiasthma medications. Ann Allergy 1991; 66: 294-299.

3. Dompeling E, Van Grunsven PE, Van Schayck CP, Folgering H, Molema J, Van Weel C. Treatment with inhaled steroids in asthma and chronic bronchitis: longterm compliance and inhaler technique. Fam Pract 1992; 9(2): 161-166.

4. Rand CS, Nides M, Cowles MK, Wise RA, Connett J, for the Lung Health Study Research Group. Long-term metered-dose inhaler adherence in a clinical trial. $A m$ J Respir Crit Care Med 1995; 152: 580-588.

5. Horn CR, Clark TJH, Cochrane GM. Compliance with inhaled therapy and morbidity from asthma. Respir Med 1990; 84: 67-70.

6. Zigmund AS, Snaith RP. The hospital anxiety and depression scale. Acta Psychiatr Scand 1983; 67: 361-370.

7. Jones PW, Quirk FH, Baveystock CM, Littlejohns P. A self-complete measure of health status for chronic airflow limitation. Am Rev Respir Dis 1992; 145: 1321-1327.

8. Bosley CM, Fosbury JA, Cochrane GM. The psycho- logical factors associated with poor compliance with treatment in asthma. Eur Respir J 1995; 8: 899-904.

9. Laird R, Chamberlain K, Spicer J. Self-management practices in adult asthmatics. NZ Med $J$ 1994; 107: 73-75.

10. Sackett DL, Snow JC. The magnitude of compliance and noncompliance. In: Haynes RB, Taylor DW, Sackett DL, eds. Compliance in Health Care. Baltimore, Johns Hopkins University Press, 1979.

11. Yellowlees PM, Alpers JH, Bowden JJ, Bryant GD, Ruffin RE. Psychiatric morbidity in patients with chronic airflow obstruction. Med J Aust 1987; 146: 305-307.

12. Jansson C, Björnsson E, Hetta J, Boman G. Anxiety and depression in relation to respiratory symptoms and asthma. Am J Respir Crit Care Med 1994; 149: 930-934.

13. Oswald NC, Waller RE, Drinkwater J. Relationship between breathlessness and anxiety in asthma and bronchitis: a comparative study. Br Med J 1970; 2: 14-17.

14. Turner J, Wright E, Mendella L., Anthonisen N, and the IPPB Study Group. Predictors of patient adherence to long-term home nebulizer therapy for COPD. Chest 1995; 108: 394-400.

15. Kinsman RA, Dirks JF, Jones NF, Dahlem NW. Anxiety reduction in asthma: four catches to general application. Psychosom Med 1980; 42(4): 397-405.

16. Campbell DA, Yellowlees PM, McLennan G, et al. Psychiatric and medical features of near fatal asthma. Thorax 1995; 50: 254-259.

17. Mellins RB, Evans D, Zimmerman B, Clark N. Patient compliance. Are we wasting our time and don't know it? Am Rev Respir Dis 1992; 146: 1376-1377. 